\title{
NB-IoT Sensor Network for Obtaining the Input Data for Hydrological Simulation Model
}

\author{
Oskars Java ${ }^{1}$, Aleksandrs Sigajevs², Juris Binde ${ }^{2}$, Michal Kepka \\ ${ }^{1}$ Institute of Social, Economic and Humanities Research, Vidzeme University of Applied Sciences, Latvia \\ ${ }^{2}$ Latvia Mobile Telephone, Latvia \\ ${ }^{3}$ New Technologies for the Information Society Research Center, University of West Bohemia in Pilsen, \\ Czech Republic
}

\begin{abstract}
The article describes the choice of appropriate network technology that provides sufficient coverage to allow the sensor network to be placed even in the remote and difficult to reach locations and the data to reach the cloud server. Further it describes the components of the sensor network, the operating principle, architecture and the processing of the data obtained to convert them into the input data used in the hydrological simulation model. The NB-IoT sensor network proposed by the authors would not only collect the data needed to operate hydrological simulation models, but, for example, could provide the data needed to forecast weather conditions, particularly if the architecture of this sensor network, because of its low cost, would be widely applied around the globe, joining a unified global sensor network.
\end{abstract}

\section{Keywords}

Sensor network, internet of things, IoT, sensor data processing, NB-IoT.

Java, O., Sigajevs, A., Binde, J. and Kepka, M. (2021) "NB-IoT Sensor Network for Obtaining the Input Data for Hydrological Simulation Model", AGRIS on-line Papers in Economics and Informatics, Vol. 13, No. 1, pp. 59-69. ISSN 1804-1930. DOI 10.7160/aol.2021.130105.

\section{Introduction}

The need for real-time access to weather data helps in monitoring and facing the escalation in the frequency and intensity of potentially dangerous events as drought, heavy rainfall, flooding and extreme temperatures (Idbella, et al., 2020). These data are also useful for operating simulation models, which allow to understand causal relationships in order to minimise the effects of human activity on the environment.

As an example, we can mention that after construction of drainage ditches, thus changing its natural hydrologic regime, many bogs in Latvia have been degraded, leaving a negative impact also on the adjacent unaffected and slightly affected hydrological regime of raised bogs and other wetlands. After drainage, bogs and its adjacent forest areas became overgrown with trees. The large volume of tree crown by interception prevents rainwater from reaching the ground, because it evaporates back into the atmosphere, as well as trees favor water absorption from the soil through the roots that further enhance the drainage effect. To restore degraded bog, first of all, it is necessary to fill up drainage ditches, but if the bog is overgrown by trees, this action may not be enough and it is indispensable to cut down part of the trees. Experimentation with forest thinning intensity in real life would take years to establish the optimal scale of intervention into the ecosystem (intensity of thinning out in order to reach the desired result by cutting down as few trees as possible) to increase saturation of soil with water that would contribute to resurgence of the bog and swampy forest biotopes. Hydrological simulation models can help to solve this issue. The available hydrological models are a simplified reflection of reality, which is useful and works sufficiently accurately in large-scale modellingbutunabletoaccurately displayall thewater flows of the specific bog ecosystem, which are vital in regional-level models (O'Keffe, et al., 2019; Staes, Rubarenzya, Meire and Willems, 2009). To deal with issues faced by existing hydrological models a new model specifically designed to simulate the bog hydrology was developed during previous research (Java, 2018). This 
model allows predicting the tree cutting influence on the ecosystem without expensive and timeconsuming experiments in real life (Java, 2018). Since the model is designed for regional modelling, so that its simulated output data is as accurate as possible, input data must also be accurate and thus collected in situ. Of course, the combination of simulation models and the proposed NB-IoT sensor network can be applied in different ecosystems to address other, different issues as well.

An IoT sensor network proposed by authors is expected to operate similar as an automatic meteorological station, but its main advantages will be that it will not need cable connection to the electrical network or the Internet, it will be compact and relatively inexpensive.

Currently, several IoT networks are operated in many locations and the coverage is growing. Choosing the appropriate IoT connectivity option for a specific need is fundamental (Ismail, Kassim, Ismail and Mohamad, 2018). There are several LPWAN (Low Power Wide Area Network) networks available in Latvia. Company Tet emphasizes that it was the first company operating the first IoT network in Latvia (tet, 2020) from 1st July 2017, which uses LoRa network technology (kursors.lv, 2017). Another company that offers IoT network solutions in Latvia by using Sigfox network is 0G Baltics (0G Baltics, 2020). One of the current weaknesses of LoRa and Sigfox technologies to support IoT solutions focused on environmental simulation and modelling is their coverage which covers only the largest cities in Latvia, leaving rural areas uncoated (tet, 2020) (Sigfox, 2020). LoRa and Sigfox coverage only in the largest cities is confined to the use of these technologies, which is a remote reading of different utility meters, which does not require high service quality and stability, as is the case with a IoT meteorological station where the data must be read several times a day instead just once a month. Unlike LoRa and Sigfox, NB-IoT (NarrowBand IoT) technology specified in Release 13 of the 3GPP in June 2016 can coexist with GSM (global system for mobile communication) and LTE (long-term evolution) under licensed frequency bands (Mekki, Bajic, Chaxel, \& Meyer, 2018). NB-IoT technology is able to use existing mobile network infrastructure, which has coverage throughout Latvia. LoRa and Sigfox uses unlicensed ISM bands (Mekki, Bajic, Chaxel and Meyer, 2018), and because NBIoT uses licensed spectrum bands (just like $3 \mathrm{G}$ and 4G) it isn't significantly affected by interference (Vodafone Group, 2017) and intervention from outside. To provide guaranteed quality of service, NB-IoT endpoint devices consume additional energy because of synchronous communication (Mekki, Bajic, Chazel and Meyer, 2017; Iqbal, Abdullah and Shabnam, 2020). Taking into account the previously mentioned, and that the NB-IoT network provides $1 \mathrm{MB}$ of data volume transmission per month with $64 \mathrm{~Kb} / \mathrm{s}$ data transmission speeds throughout the territory of Latvia using secure data transmission connection (Latvijas Mobilais Telefons, 2020), it can be concluded that the most appropriate IoT network in Latvia circumstances is NB-IoT, provided by Latvia Mobile Telephone (LMT).

\section{Materials and methods}

This article is based on literature research to find the best way to build an IoT sensor network to collect the input data for simulation models.

It can be said that there is no need to install new sensors in order to gather and store meteorological data, since different climate data services are operated, for example on the Copernicus satellite base. The atmospheric reanalyses (ERA5) of the European Centre for Medium-Range Weather Forecasts (ECMWF) dataset was produced on behalf of Copernicus Climate Change Service (C3S) and was generated entirely within the Climate Data Storage (CDS) Toolbox (ECMWF, 2020). This historical dataset might seem suitable for hydrological modelling, but if we talk about modelling related to a specific point, such as a bog, its resolution in the $0.5 \times 0.5$ degree grid (ECMWF, 2020) is not sufficient. Satellite precipitation products still suffer from quantitative uncertainties and biases compared to ground data (Pellarin, et al., 2020), but parameterizations and adequate initialization of outputs from hydrological models is limited due to lack of sufficient in situ data (Ndehedehe, 2019).

Sensors that collect meteorological data for hydrological simulation modelling often need to be placed in locations away from any infrastructure so they can detect any changes in the environment and notify the user of any events that have occurred. Then these daily changes need to be captured and uploaded to the cloud server so the user could then use it to get the periodical data from sensors.

IoT owes much of its success to the widespread distribution of Internet communication networks (Idbella, et al., 2020). Leading mobile operators, global vendors and developers are launching NB-IoT network as an integral part of their longterm 5G IoT strategies (GSMA, 2018). NB-IoT is 
an innovative network dedicated entirely to the IoT. This network is public and uses existing LTE cells, the same ones that were used for GSM mobile phones years ago (Idbella, et al., 2020). IoT sensors are low cost, use low data volumes, require long battery lives and often operate in remote and hard to reach locations. Mobile IoT delivers connectivity on a massive scale today and will continue to do so in the $5 \mathrm{G}$ future (GSMA, 2018). With the IoT new business models can be built, new services offered or efficiency increased (Deutsche Telekom AG, 2019). In the context of the hydrological model, IoT sensors would increase efficiency, as compared to the standard meteorological station. The IoT sensor network would use a significantly lower amount of data transmitted and electricity consumed.

The NB-IoT network standard is a genuine game changer to IoT solution providers, as it expands the technical possibilities to make massive IoT deployments economically feasible (Deutsche Telekom AG, 2019). NB-IoT is an open standard based on LTE. It has the backing of major equipment manufacturers, and is based on familiar technology for easier integration into existing infrastructure and processes (Vodafone Group, 2017).

The NB-IoT technology can work with lower signal strength compared to GPRS technology (Deutsche Telekom AG, 2019) and as it uses licensed spectrum bands (just like $3 \mathrm{G}$ and $4 \mathrm{G}$ ) it is not significantly affected by interference (Vodafone Group, 2017). Due to these facts, NB-IoT network is suitable for environmental monitoring in remote places where signal coverage is problematic.

There are many ways to reduce power usage and achieve long battery lifespans. Most simply, you can keep the device in idle mode or deep sleep, so it doesn't waste power chatting to the network between communication sessions. Power management is fundamentally a balance between message frequency, device sleep cycles and business case needs (Vodafone Group, 2017). Because an IoT battery can serve up to 10 years (assuming equivalent of two AA batteries and typical pattern in base coverage cell) (Deutsche Telekom AG, 2019), the question arises whether, given that technology is changing rapidly, it is worth investing in this technology. NB-IoT is a ThirdGeneration Partnership Project (3GPP) standard closely related to LTE technology, as a result, it can be deployed on almost all LTE base stations, alongside LTE traffic, through a straightforward software upgrade to the radio access network (RAN), it gives the reassurance that it is a low-risk, long-term technology (Vodafone Group, 2017).

\section{Results and discussion}

Meteorological sensor networks are data-centric networks, which process data for continuous meteorological data collected by sensors (Yang et al., 2019). In order to collect the input data required for the simulation model of the hydrological regime, the sensor network must obtain groundwater level measurement (mm) and meteorological data such as precipitation in form of rain or snow $(\mathrm{mm})$, wind speed $(\mathrm{m} / \mathrm{s})$, solar radiation $\left(\mathrm{W} / \mathrm{m}^{2}\right)$, air temperature $\left({ }^{\circ} \mathrm{C}\right)$, relative humidity $(\%)$. If the modelling was performed in a geographically larger area as an average Latvian bog and there were several such sensor networks, it would also be important to gather information on the wind direction as well.

\section{Sensor network components}

Many parameters, such as average daily air temperature, are currently easy to calculate because measurements can be automatically performed at a short time interval (once every 0.25 seconds (Met Office College, 2020)), stored digitally, and divided by the amount of measurements with the number of measurements. In author's view, this method does not correspond to the nature of IoT sensors, one of the main advantages of which is the ability to place them in remote and/or difficultto-reach areas to measure and transmit data in a way that consumes as little energy as possible to extend battery life. Publication describing studies of IoT meteorological sensors often use a 3-hour interval between measurements (Liu et al., 2018), or a 10-minute interval based on correct measurement records (Awandallah, Moure and Torres-González, 2019). In the rest of the chapter, authors describe the choice of IoT sensors and their provisional operating principle, which would allow one to find a balance between the frequency of measurements, consumption of energy and amount of data transferred.

\section{Radio modem and antenna}

A radio modem with an antenna is required so that all sensors can be integrated into a single system, controlled and data can be transferred. Because of the open code hardware and software, authors have chosen Arduino's ecosystem as the most suitable for a radio modem and antenna solution. For example, the SODAQ SARA AFF R412M developer board compliant with IoT standard Arduino formfactor is suitable. It has a powerful 32 bits microcontroller, $256 \mathrm{~KB}$ flash memory, two grove sockets to easily connect any sensor, two JST connectors to connect battery and solar 
panel, onboard charge circuit, accelerometer, GPS, NB-IoT and antenna. When connecting a battery and SIM card to the developer board, it becomes a modem that is capable of operating autonomously and does not require manual intervention. As NB-IoT supports bi-directional communication where orthogonal frequency division multiple access (OFDMA) is used for downlink, and single carrier frequency division multiple access (SC-FDMA) is used for uplink (Chaudhari, Zennaro, \& Borkar, 2020), the updates can be done remotely by connecting from the workstation.

\section{Battery}

Mobile IoT radio modem usually draws bursts of current for a short time, also called pulse currents (Texas Instruments Inc., 2020) to hundreds of milliamps in a matter of tens of microseconds (Tektronix, 2015). A battery needs to be dimensioned to deliver such currents also in potentially extreme temperature conditions (very cold or hot environments). On the other hand, one has to consider the battery self-discharge and the capacity loss during storage. For a battery lifetime estimation, several other factors should be considered, e.g., cut-off voltages, battery efficiency, leaking currents, temperature effects etc.

In order to achieve very long battery lifetimes and reduce maintenance cycles for IoT applications, it is recommended to use primary lithium chemistries such as SAFT LS 26500 3.6 V Primary lithium-thionyl chloride (Li-SOCI2).

\section{Groundwater level}

Groundwater level measurements can be performed with two types of IoT sensors, a water pressure sensor such as SEN0257 DFROBOT or a laser distance sensor such as OKY3240-1 OKYSTAR. In both cases, it is necessary to drill holes in which to insert the shells to create wells. In the case of a pressure sensor, it must be placed at the bottom of the well and the groundwater must be calculated by the water pressure, which varies depending on the weight of the water above it. If a laser sensor is used, it must be attached to the well cover, a floating surface must be placed in the water for the determination of the distance to the surface of the water.

The hydraulic conductivity of acrotelm (top layer of peat soil up to depth of approximately $50 \mathrm{~cm}$ ) is $330 \mathrm{~cm} /$ day, but is rapidly decreasing from $9 \mathrm{~cm} /$ day at depth of $1.2 \mathrm{~m}$ to $0.16 \mathrm{~cm} /$ day at a depth equal to or greater than $2 \mathrm{~m}$ (Custers and Graafstal, 2005). Given the hydraulic conductivity of acrotelm and the presence of drainage ditches in degraded bogs, fluctuations in groundwater can reach several tens of centimetres within one day, so the author recommends that groundwater measurements be performed at the same interval as the last measurements (excluding the amount of precipitation) to obtain the average daily value, as the simulation model generates output data as the daily value.

\section{Mean air temperature and relative humidity}

Statistical tests shall indicate that the measurements have been made at a lower interval, the more accurate the average daily temperature value. In order to find a balance between the number of measurements and the life of the battery, authors identified the Mannheimer-Hour method as the most appropriate method to determine the average daily value, which can be expressed by the Kämtz`schen equation:

$T M=(T 07+T 14+2 * T 21) / 4$

Where $T M$ is the average daily air temperature, T07, $T 14$ and $T 21$ denotes the air temperature at 7:00, 14:00 and 21:00 respectively. A double weight is assigned to the temperature at 21:00 for the average air temperature to be as precise as possible (Behrendt and Zimmermann, 2008). A very low proportion of variation R2 0.99 with RMSE 0.06 was observed when comparing the average daily temperature values of the air temperature calculated from data with a reading interval of 4 times per second and MannheimerHour method using only three readings per day.

Since relative humidity is closely associated with air temperature due to the amount of water vapour in the air, expressed as a percentage of the maximum amount of steam that the air could hold at the given temperature (Yahia, 2019), authors suggest that, for measurements of relative humidity Mannheimer Hour method with R2 of 0.95 is applicable. To measure air temperature and relative humidity, such as the integrated temperature and humidity IoT sensor Grove SHT31 with typical accuracy of $\pm 0.3{ }^{\circ} \mathrm{C}$ for temperature and $\pm 2 \%$ error for humidity is appropriate (Seeed Technology Co., Ltd., 2020).

\section{Precipitation}

Precipitation gauges are used in meteorological stations that capture rainfall through the funnel, deliver it to special buckets in which they are weighted, read, and sent to the server as shown in Figure 1. Such equipment is not suitable for the IoT sensor network as it requires constant electricity supply and electric heating during 
a period of negative air temperature. Since a funneltype rain gauge is unable to determine the type of precipitation, only the amount of precipitation in millimetres should be relied on either the air temperature (positive or negative) or the additional microwave radar should be added to determine the type of precipitation.

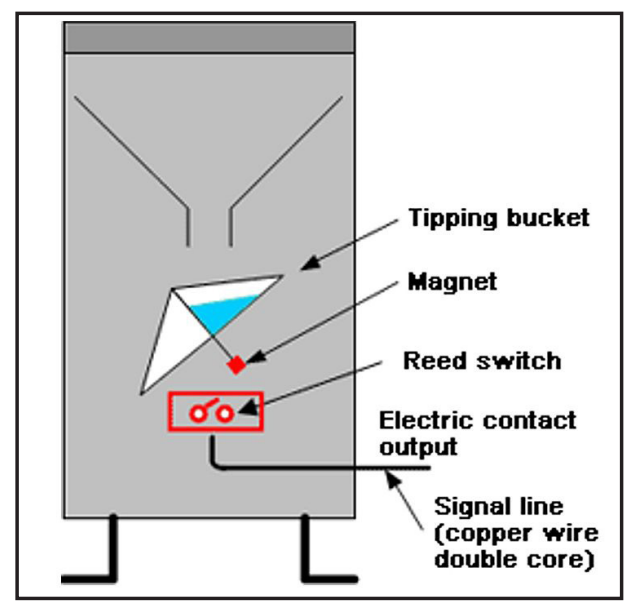

Source: Furukawa Electric Co., LTD, 2011

Figure 1: Precipitation gauge.

Laser precipitation sensors such as OTT Parsel2 LUFFT are available on the market. For this distrometer, laser technology provides an opportunity to calculate type, amount, intensity and kinetic energy of the precipitation (Lufft, 2020). By exploring the range of IoT laser sensors available, the authors found no one capable of measuring both the size and velocity of the falling particles at the same time, by which it would be possible to calculate the amount of rainfall in millimetres, so an alternative method was sought.

According to authors, the best way to create an alternative IoT distrometer is to use a precipitation sensor, such as OKY3435 OKYSTAR, which generates a signal 0 or 1 , as a switch that, depending on the presence of absence of precipitation, would turn on or off a low power doppler microwave radar BGT24LTR11, which would perform measurements until a signal with value of 0 would be received from the precipitation sensor. In order to further reduce the battery consumption, cloud technology allows the system to connect one of the online weather forecasts, such as the national portal meteo.lv/laiks, which, when precipitation is not forecast, turns off the precipitation sensor, but when precipitation is forecast, turns it into standby mode.

\section{Wind speed}

For wind speed measurements, it is necessary to select an IoT anemometer, such as SEN0170 DFROBOT, which consumes little energy and generates an output signal with a voltage from 0 to $5 \mathrm{~V}$. The wind speed is determined according to the voltage output curve from 0 to $30 \mathrm{~m} / \mathrm{s}$ (DFROBOT, 2020). Given that wind can give gusts, wind speed is set to be the mean of two-minute measurements (National Weather Service, 2020). This means that, in order to obtain the daily wind speed, measurements should be made once an hour over a two-minute period of 0.25 second interval, the mean value for each hour should be calculated and the daily mean values should be divided by the number of hours.

\section{Solar radiation}

The hydrological simulation model developed by Java (2018) uses solar radiation in the equations that calculate the transpiration of the forest stand and the melting of snow. In addition to solar radiation, transpiration is also affected by other meteorological conditions such as: air temperature, wind speed and atmospheric humidity deficit (difference between saturated water vapour pressure and actual water vapour pressure). The melting of snow, excluding solar radiation, is affected by air temperature.

Solar radiation measuring instruments are expensive. From the 31 automatic observation stations located on the territory of Latvia, only 7 have measuring instruments installed, measuring total solar radiation in Watts per square meters (Valsts Vides ǵeologijas un meteorologijas centrs, 2020). Several sources mention that approximately $6 \%$ of total solar radiation reaching the Earth's surface is UV radiation (Gharehpetian and Mohammad Mousavi Agah, 2017; Jacobsen and Dangles, 2017), therefore, given that solar radiation is not the only meteorological factor affecting transpiration and melting of snow, the author proposes that IoT UV sensors, such as Grove I2C UV light Sensor VemL6070, to be used for solar radiation measurements.

To reduce the electricity consumption, the author proposes to connect a light sensor, such as SEN0043 DFROBOT, to the sensor network, which would measure the light intensity once an hour. Shortly after sunset and before sunrise, the light intensity is $10 \mathrm{~lx}$ (Schlyter, 2017), so this is assumed as a reference value, because when it is exceeded, the sun is visible on the horizon, so radiation 
from it reaches the Earth together with the light. Above 10 lx the light sensor instructs the UV sensor to take the measurement. Daily measurements must be made until the light intensity drops to $10 \mathrm{~lx}$ and must be counted together and corrected by a factor of 16.7 to obtain a result close to total solar radiation.

\section{Sensor network body}

In order to protect the modem and the battery from external climatic conditions, an airtight junction box has been used, which is available in any hardware store. One rain sensor holder printed out with a $3 \mathrm{D}$ printer was attached to the junction box, allowing the rain sensor to be installed at an angle of 45 degrees so that the water could easily drain from it and allow the sensor to dry quickly after the precipitation has ended. The second rain sensor holder was used to attach UV and light sensors at an angle that prevents snow from accumulating and blocking the sunlight. A solar radiation shield was printed out with a $3 \mathrm{D}$ printer and installed under the junction box to protect temperature and relative air temperature sensors. An anemometer was attached to the top of the junction box. To facilitate 3D printing, the authors used the templates available on thingiverse.com.

\section{Sensor network architecture}

NB-IoT sensor network architecture (see Figure 2) consists of sensors, controllers, sensor interface, data format interface, batteries, radio modem and antennas described in the previous section, which together form a sensor network.

Sensors are integrated into a single system and placed in the selected remote location and are connected to the radio modem. The architecture uses NB-IoT network to transfer data from device to mobile cell tower. Using the MQTT protocol, data from a mobile cell tower is transferred to the data cloud where they can be stored and analysed. In the cloud, raw data is decoded into measurement data. The modem allows the modeller to interact with the devices attached to it. Once the communication mode is set up and the cloud server is configured, the communication takes place between sensors and the cloud server. The architecture provides that the modeller can access data stored in the cloud using the Internet browser and, if necessary, remotely change the interface between the sensors and the data format.

\section{Meteorological data storage}

The authors believe that sensor network data should

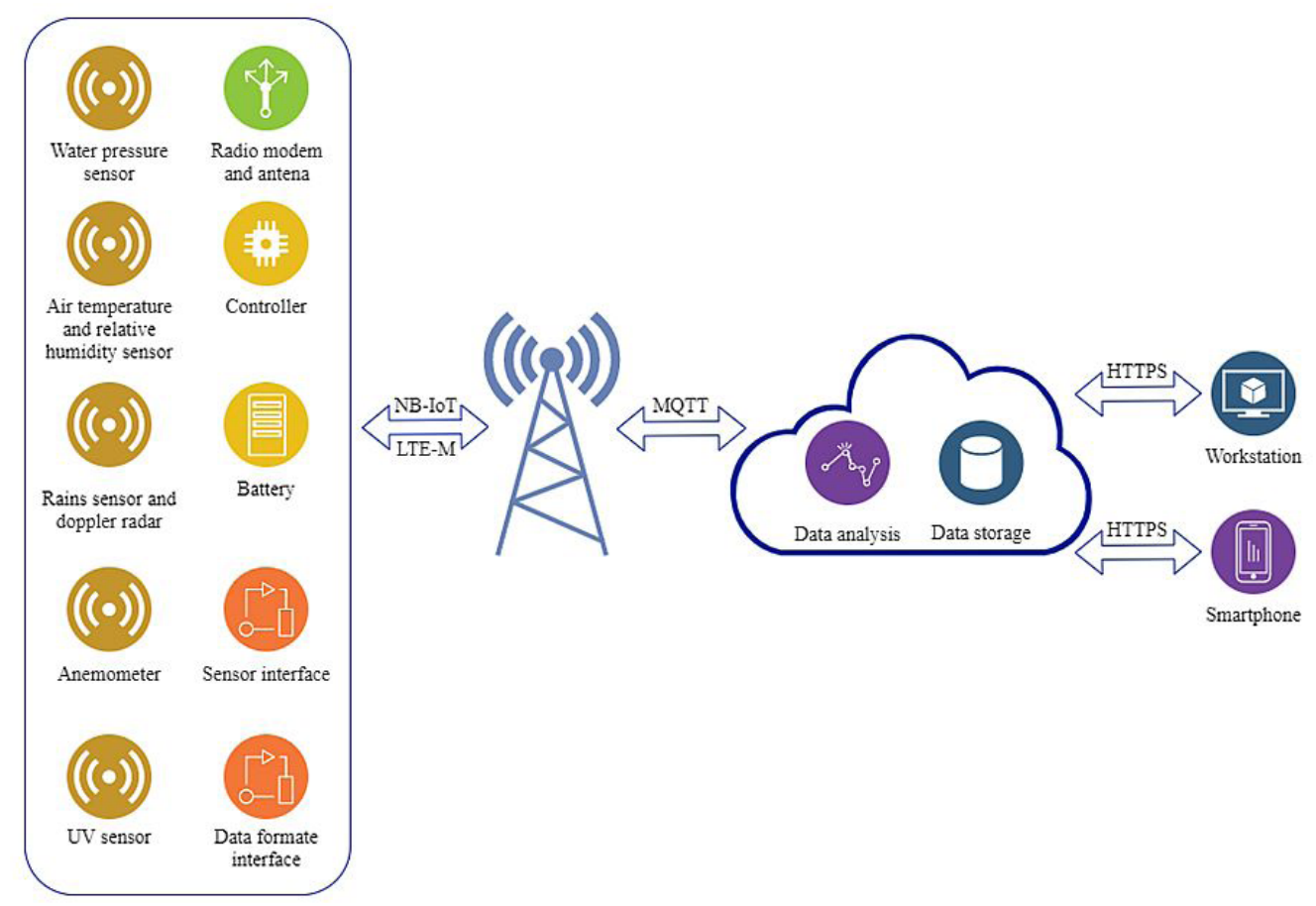

Source: Authors

Figure 2: NB-IoT sensor network architecture for obtaining hydrological simulation model input data. 
be stored in a data storage located in the cloud. Cumulocity has been a leading application enabling platform and IoT management platform since its launch in 2010 (i-SCOOP, 2020). Cumulocity includes all tools and capabilities needed to manage IoT sensor network through the cloud:

- Secure connection;

- Device management;

- Self-service analytics;

- Rapid enterprise application integration;

- Tools to accelerate smart product development;

- Advanced analytics tooling for data experts;

- Lifecycle of machine learning models management (Software AG, 2020).

Once the sensor network is registered on the Cumulocity IoT platform, it is necessary to change the communication interval to 24 hours, minimizing the intervals for sending information to the cloud and back, while defining it so small that it is possible to identify errors and resolve them in a timely manner. This is important in order not to lose data for a longer period of time, as it can be in the case when the sensor network is installed in a remote location and left to operate independently there. If there had been a failure, the researcher would only find it out when visiting the site to read the data.

Raw sensor data can be downloaded in a CSV and Excel file that stores the data as shown in Table 1.

Data can be downloaded from the Cumulocity IoT platform separately for each sensor. The authors uses the Stella Architect model for simulations, whose input data is uploaded via single file in CSV format, so it is important that the data are formatted in the way that the simulation model supports.

Python script was designed and developed to process sensor data from the Cumulocity
IoT platform to appropriately format input data for the simulation model. The script determines which Cumulocity IoT user account must be logged in, which sensor data for which time period should be collected, what mathematical steps should be taken to calculate average daily values, how to store data in the CSV format of the simulation model, to which email address data should be sent.

Python script runs on the server of the Vidzeme University of Applied Sciences. If the simulation model itself had been developed in Python script and located on the same server, it would be possible to upload the data to the simulation model without email, which would allow real-time simulations, only to change a few lines in the data processing script. An example of how the input data generated by the Python script to the CSV file is shown in Table 2.

A new data point with an average measurement value is created in the input data file for each subsequent day. New types of measurements can be added to the table by adding new columns, but attention should be paid to the fact that the column names must match the names of the converters defined in the simulation model, otherwise it will not be able to recognize the data and store them in the corresponding converters.

The Python data processing script contains several values that can be configured as needed, for example, the recipient's email or data sending period from seven days to a shorter or longer time as needed can be changed.

In order to make the data collected by the sensor network publicly available, it is intended to publish the processed data to the Latvian Open Data Portal (data.gov.lv) in the future or a similar international site, as well as to use the data uploaded to the portal of other users to supplement the data collected by the sensor network, providing an opportunity to build new simulation models and knowledge.

\begin{tabular}{|l|c|l|l|c|c|}
\hline time & source & device_name & fragment.series & value & unit \\
\hline 2020-08-01T09:00:26.563Z & 1940 & MQTT Device sodaq001 & Humidity.Relative Humidity & 52 & $\% \mathrm{RH}$ \\
\hline 2020-08-01T14:00:44.644Z & 1940 & MQTT Device sodaq001 & Humidity.Relative Humidity & 43 & $\% \mathrm{RH}$ \\
\hline 2020-08-01T21:00:10.598Z & 1940 & MQTT Device sodaq001 & Humidity.Relative Humidity & 58 & $\% \mathrm{RH}$ \\
\hline
\end{tabular}

Source: Authors

Table 1: Cumulocity raw data output.

\begin{tabular}{|l|c|l|}
\hline Date & Average Temperature & Average humidity \\
\hline 01.08 .2020 & 17.92 & 52.75 \\
\hline
\end{tabular}

Source: Authors 


\section{Conclusion}

The low cost of IoT sensors and the NB-IoT network data technology, small size and long battery life open up opportunities for wider acquisition of high-quality in-situ data that can be used for simulation models. While, based on cloud computing algorithms, it is not possible to create a single global meteorological data repository with a sufficient resolution to make the data available and usable to operate high precision local simulation models, IoT sensor networks are suitable for obtaining these data and could become part of a global sensor network in the future. A sensor system that collects input data for the hydrological system dynamics model has the potential to use machine learning techniques to calibrate sensors, to look for faulty sensors, to know in advance that maintenance is required and to predict future weather forecasts if needed.

Other IoT sensors and developer boards similar to ones offered by the authors can be used to collect in-situ data to support hydrological models with input data taking into account the proposed architecture and working principles. The exception is the microwave doppler radar for which no alternative was available on the market during the development of the sensor network. The proposed architecture of the sensor network for data collection was tested by a field campaign during the last year and results of this campaign show effectiveness of data collection and data transfer by existing NB-IoT network. Collected data from this campaign were successfully used in the simulation and model results show adequate coverage of input data for running defined simulations.

\section{Acknowledgements}

This publication was supported by the project LO1506 of the Czech Ministry of Education, Youth and Sports under the program NPU I.

\section{Corresponding authors}

IMg.sc.comp. Oskars Java

Institute of Social, Economic and Humanities Research

Vidzeme University of Applied Sciences, Cēsu Street 4, Valmiera, LV-4201, Latvia

E-mail: oskars.java@va.lv

\section{References}

[1] OG Baltics (2020) "Company and Technology". [Online]. Available: https://sigfox.lt// [Accessed: 10 Nov 2020].

[2] Awandallah, S., Moure, D. and Torres-González, P. (2019) "An Internet of Things (IoT) Application on Volcano Monitoring", Sensors, Vol. 19, No. 21, pp. 1-29. ISSN 1424-8220. DOI 10.3390/s19214651.

[3] Behrendt, J. and Zimmermann, K. (2008) "Qualitätskontrolle historischer Klimadaten", Klimastatusbericht 2008, pp. 119-125. E-ISSN 1616-5063. ISSN 1437-7691. ISBN 978-3-88148-441-1.

[4] Chaudhari, B. S., Zennaro, M. and Borkar, S. (2020) "LPWAN Technologies: Emerging Application Characteristics, Requirements, and Design Considerations", Future Internet, Vol. 12, No. 46, pp. 1-25. ISSN 1999-5903. DOI 10.3390/fi12030046.

[5] Custers, J. and Graafstal, H. (2005) "Characterization of the water flow in a pool-ridge microtope in a bog", A case study of Männikjärve bog, Estonia. Wageningen University.

[6] Deutsche Telekom AG (2019) "Mobile IoT guide. How NB-IoT and LTE-M are helping the IoT take off", Bonn. [Online]. Available: https://www.gsma.com/iot/resources/ mobile-iot-guide-how-nb-iot-and-lte-m-are-helping-the-iot-take-off/[Accessed: 5 Nov 2020].

[7] DFROBOT (2020) "Wind Speed Sensor Voltage Type 0-5V SKU SEN0170". [Online]. Available: https://wiki.dfrobot.com/Wind_Speed_Sensor_Voltage_Type_0-5V_SKU_SEN0170 [Accessed: 14 Dec 2020].

[8] Dictionary.com, LLC. (2020) "Relative humidity". [Online]. Available: https://www.dictionary.com/ browse/relative-humidity [Accessed: 12 Nov 2020]. 
[9] ECMWF (2020) "Near surface meteorological variables from 1979 to 2018 derived from biascorrected reanalysis". [Online]. Available: https://cds.climate.copernicus.eu/cdsapp\#!/dataset/ derived-near-surface-meteorological-variables?tab=overview [Accessed: 4 August 2020].

[10] Furukawa Electric Co., LTD. (2011) "Optical Fiber Rain Gauge Commercialized, Japan Meteorological Agency Verification Obtained, and Sales Launched". [Online]. Available: https:// www.furukawa.co.jp/english/what/2011/comm_111207.htm [Accessed: 4 Aug 2020].

[11] Gharehpetian, G. B. and Mohammad Mousavi Agah, S. (2017) "Distributed Generation Systems. Design, Operation and Grid Integration", Elsevier Inc., 588 p. ISBN 9780128042083 , E-ISBN 9780128042632.

[12] GSMA (2018) "NB-IoT and LTE-M in the context of 5G. Mobile IoT in the 5G future", London. [Online]. Available: https://www.gsma.com/iot/resources/mobile-iot-5g-future/ [Accessed: 10 Aug 2020].

[13] Guardian News and Media Limited (2020) "Decline in aircraft flights clips weather forecasts ' wings". [Online]. Available: https:/www.theguardian.com/news/2020/apr/09/decline-aircraftflights-clips-weather-forecasters-wings-coronavirus [Accessed: 4 Aug 2020].

[14] Ha, J.-H., Im, Y.-H., Kim, H.-H., Sim, N.-J. and Yoon, Y. (2018) "Error Correction of Meteorological Data Obtained with Mini-AWSs Based on Machine Learning", Advances in Meteorology, pp. 1-8. E-ISSN 1687-9317, ISSN 1687-9309. DOI 10.1155/2018/7210137.

[15] Hoyos, C. D., Ceballos, L. I., Pérez-Carrasquilla, J. S., Sepulveda, J., López-Zapata, S. M., Zuluaga, M. D., Velásquez, N., Herrera-Mejía, L., Hernández, O., Guzmán-Echavarría, G. and Zapata, M. (2019) "Meteorological conditions leading to the 2015 Salgar flash flood: Lessons for vulnerable regions in tropical complex terrain", Natural Hazards and Earth System Sciences, Vol. 19, No. 11, pp. 2635-2665. ISSN 16849981. DOI 10.5194/nhess-19-2635-2019.

[16] Hua, W., Zhou, L., Nicholson, S. E., Chen, H. and Qin, M. (2019) "Assessing reanalysis data for understanding rainfall climatology and variability over Central Equatorial Africa", Climate Dynamics, Vol. 53, No. 1-2, pp. 651-669. E-ISSN 1432-0894, ISSN 0930-7575. DOI 10.1007/s00382-018-04604-0.

[17] Idbella, M., Iadaresta, M., Gagliarde, G., Mennella, A., Mazzoleni, S. and Bonanomi, G. (2020) "AgriLogger: A New Wireless Sensor for Monitoring Agrometeorological Data in Areas Lacking Communication Networks", Sensors, Vol. 20, pp. 1-13. E-ISSN 1424-8220. DOI 10.3390/s20061589.

[18] Iqbal, M., Abdullah, A. and Shabnam, F. (2020) "An Application Based Comparative Study of LPWAN Technologies for IoT Environment", 2020 IEEE Region 10 Symposium, pp. 1857-1860. DOI 10.1109/TENSYMP50017.2020.9230597.

[19] i-SCOOP (2020) "Cumulocity IoT recognized as IoT platform leader, launches new release". [Online]. Available: https://www.i-scoop.eu/cumulocity-iot/ [Accessed: 4 Aug 2020].

[20] Ismail, N. L., Kassim, M., Ismail, M. and Mohamad, R. (2018) "A review of low power wide area technology in licensed and unlicensed spectrum for IoT use cases", Bulletin of Electrical Engineering and Informatics, Vol. 7, No. 2, pp. 183-190. E-ISSN 2302-9285, ISSN 2089-3191. DOI 10.11591/eei.v7i2.1174.

[21] Jacobsen, D. and Dangles, O. (2017) "Ecology of High Altitude Waters", Oxford: Oxford University Press. ISBN 13 9780198736868. DOI 10.1093/oso/9780198736868.001.0001.

[22] Java, O. (2018) "Restoration of a Degraded Bog Hydrological Regime Using System Dynamics Modeling", pp. 1105-1113, Prague: CBU International Conference on Innovations in Science and Education. DOI 10.12955/cbup.v6.1301.

[23] kursors.lv (2017) "Lattelecom Rīgā izbūvējis lietu interneta tīklu. Ielādēts no Tehnoloǵiju ziņas, apskati un attieksme". [Online]. Available: https://kursors.lv/2017/07/01/lattelecom-riga-izbuvejislietu-interneta-tiklu/ [Accessed: 16 Oct 2020]. (in Latvian).

[24] Latvijas Mobilais Telefons (2020) "NB-IoT". [Online]. Available: https://bizness.lmt.lv/lv/nbapraksts [Accessed: 16 Oct 2020]. 
[25] Liu, W., Zhang, C., Liu, P., Yan, M., Wnag, B., Zhang, J. and Higgs, R. (2018) "Application of Temperature Prediction Based on Neural Network in Intrusion Detection of IoT", Security and Communication Networks, Vol. 2018, pp. 1-10. E-ISSN 1939-0122, ISSN 1939-0114. DOI 10.1155/2018/1635081.

[26] Lufft (2020) "Technical Data. OTT Parsivel2 - Laser Weather Sensor". [Online]. Available: https:// www.lufft.com/products/precipitation-sensors-287/ott-parsivel2-laser-weather-sensor-2399/ productAction/outputAsPdf/ [Accessed: 23 Oct 2020].

[27] Mashal, A. F. and Fernald, A. G. (2020) "Identifying Capabilities and Potentials of System Dynamics in Hydrology and Water Resources as a Promising Modeling Approach for Water Management", Water, Vol. 12, No. 1342, pp. 1-23. ISSN 2073-4441. DOI 10.3390/w12051432.

[28] Mekki, K., Bajic, E., Chaxel, F. and Meyer, F. (2017) "A comparative study of LPWAN technologies for large-scale IoTdeployment", ICT Express, Vol. 5, No. 1, pp. 1-7. ISSN 2405-9595. DOI 10.1016/j.icte.2017.12.005.

[29] Met Office College (2020) "How we measure wind". [Online]. Available: https://www.metoffice.gov. uk/weather/guides/observations/how-we-measure-wind [Accessed: 23 Oct 2020].

[30] Mwakwate, C. B., Malik, H., Alam, M. M., Moullec, Y. L., Parad, S. and Mumtaz, S. (2019) "Narrowband Internet of Things (NB-IoT): From Physical (PHY) and Media Access Control (MAC) Layers Perspectives", Sensors, pp. 1-34. ISSN 1424-8220. DOI 10.3390/s19112613.

[31] National Weather Service (2020) "Wind Speed". [Online]. Available: Search: https://forecast.weather. gov/glossary.php?word=WIND\%20SPEED [Accessed: 23 Oct 2020].

[32] Ndehedehe, C. E. (2019) "The water resources of tropical West Africa: problems, progress, and prospects", Acta Geophysica, Vol. 67, No. 2, pp. 621-649. ISSN 18957455. DOI 10.1007/s11600-019-00260-y.

[33] O'Keffe, J., Marcinkowski, P., Utratna, M., Pinewski, M., Kardel, I., Kundzewicz, Z. W. and Okruszko, T. (2019) "Modelling Climate Change's Impact on the Hydrology of Natura 2000 Wetland Habitats in the Vistula and Odra River Basins in Poland", Water, Vol. 11, No. 10, pp. 1-24. ISSN 2073-4441. DOI 10.3390/w11102191.

[34] Onal, A. C., Sezer, O. B., Ozbayoglu, M. and Dogdu, E. (2017) "Weather Data Analysis and Sensor Fault Detection Using an Extended IoT Framework with Semantics, Big Data and Machine Learning", 2017 IEEE International Conference on Big Data, pp. 1-10. Boston. DOI 10.1109/BigData.2017.8258150.

[35] Pellarin, T., Román-Cascón, C., Baron, C., Bindlish, R., Brocca, L., Camberlin, P.,, FernándezPrieto, D., H. Kerr, Y. H., Massari, Ch., Panthou, G., Perrimond, B., Philippon, N. and Quantin, G. (2020) "The precipitation inferred from soil moisture (PrISM) near real-time rainfall product: Evaluation and comparison", Remote Sensing, Vol. 12, No. 3, pp. 1-18. ISSN 2072-4292. DOI 10.3390/rs12030481.

[36] Schlyter, P. (2017) "How bright are natural light sources?". [Online]. Available: http://stjarnhimlen. se/comp/radfaq.html\#10 [Accessed: 25 Oct 2020].

[37] Seeed Technology Co., Ltd. (2020) "Groove - Temperature \& Humidity Sensor (SHT31)". [Online]. Available: $\quad$ https://www.seeedstudio.com/Grove-Temperature-Humidity-Sensor-SHT31.html [Accessed: 28 Oct 2020].

[38] Sigfox (2020) "Coverage". [Online]. Available: https://www.sigfox.com/en/coverage [Accessed: 26 Oct 2020].

[39] Software AG (2020) "Cumulocity IoT capabilities". [Online]. Available: https://www.softwareag. cloud/site/capability/cumulocity-iot.html\#/ [Accessed: 25 Oct 2020].

[40] Staes, J., Rubarenzya, M. H., Meire, P. and Willems , P. (2009) "Modelling hydrological effects of wetland restoration: a differentiated view", Water Science \& Technology, pp. 433-441. ISSN 0273-1223. DOI 10.2166/wst.2009.884. 
[41] Takami, G., Tokuoka, M., Goto, H. and Nozaka, Y. (2016) "Machine Learning Applied to Sensor Data Analysis", Yokogawa Technical Report English Edition, Vol. 59, No. 1, pp. 27-30. ISSN 0911-8977.

[42] Tektronix (2015) "11 Power Consumption Measuremet Techniques". [Online]. Available: https:// www.tek.com/document/how-guide/11-power-consumption-measurement-techniques [Accessed: 3 Aug 2020].

[43] tet (2020) "Pirmais lietu interneta tīkls Latvijā". [Online]. Available: https://iot.tet.lv/lv [Accessed: 14 Sept 2020]. (in Latvian).

[44] Texas Instruments Inc. (2020) "NB-IoT Power Topologies for Smart Meter Wireless Modules Using Primary Cells Reference Design". Dallas. [Online]. Available: https://www.ti.com/lit/pdf/tidueo0b [Accessed: 14 Sept 2020]. (in Latvian).

[45] Valsts Vides ǵeolog̣ijas un meteoroloǵijas centrs (2020) "Novērojumu stacijas". [Online]. Available: https://www.meteo.lv/meteorologijas-staciju-karte/?nid=460 [Accessed: 15 Oct 2020]. (in Latvian).

[46] Vodafone Group (2017) "Narrowband IoT: pushing the boundaries of IoT". [Online]. Available: https://www.vodafone.com/business/news-and-insights/white-paper/narrowband-iot-pushing-theboundaries-of-iot [Accessed: 3 Aug. 2020].

[47] Xie, X., Wu, D., Liu, S. and Li, R. (2017) "IoT Data Analytics Using Deep Learning", Computer Science, Networking and Internet Architecture, pp. 1-11. arXiv:1708.03854.

[48] Yahia, E. M. (2019) "Postharvest Technology of Perishable Horticultural Commodities", Elsevier, E-ISBN 9780128132777 , ISBN 9780128132760.

[49] Yamamoto, K., Togami, T., Yamuchi, N. and Ninomiya, S. (2017) "Machine Learning-Based Calibration of Low-Cost Air Temperature Sensors Using Environmental Dat", Sensors, pp. 1-16. ISSN 1424-8220. DOI 10.3390/s17061290.

[50] Yang, M., He, W., Zhang, Z., Xu, Y., Yang, H., Chen, Y. and Xu, X. (2019) "An efficient storage and service method for multi-source merging meteorological big data in cloud environment", EURASIP Journal on Wireless Communications and Networking, Vol. 241, pp. 1-12. ISSN 1687-1499. DOI 10.1186/s13638-019-1576-0. 